OPEN ACCESS

Edited by:

Ann Dowker

University of Oxford, United Kingdom

Reviewed by:

Mirjana Djordjevic,

University of Belgrade, Serbia

Dan Tomasulo,

Columbia University, United States

*Correspondence:

Udeme Samuel Jacob

udeme01@gmail.com

Jace Pillay

jacep@uj.ac.za

Esther Olufunke Oyefeso

estheroyefeso@gmail.com

Specialty section: This article was submitted to

Developmental Psychology, a section of the journal

Frontiers in Psychology

Received: 09 March 2021

Accepted: 30 March 2021

Published: 11 May 2021

Citation:

Jacob US, Pillay $J$ and Oyefeso EO (2021) Attention Span of Children With Mild Intellectual Disability: Does Music Therapy and Pictorial Illustration Play Any

Significant Role?

Front. Psychol. 12:677703. doi: 10.3389/fpsyg.2021.677703

\section{Attention Span of Children With Mild Intellectual Disability: Does Music Therapy and Pictorial Illustration Play Any Significant Role?}

\author{
Udeme Samuel Jacob ${ }^{1,2 *}$, Jace Pillay ${ }^{3 *}$ and Esther Olufunke Oyefeso ${ }^{2 *}$ \\ ' Postdoctoral Research Fellow, South African Research Chair: Education and Care in Childhood, Faculty of Education, \\ University of Johannesburg, Johannesburg, South Africa, ${ }^{2}$ Department of Special Education, Faculty of Education, \\ University of Ibadan, Ibadan, Nigeria, ${ }^{3}$ South African Research Chair in Education and Care in Childhood, Faculty \\ of Education, University of Johannesburg, Johannesburg, South Africa
}

This study investigated the effects of music therapy and pictorial illustration on the attention span of children with mild intellectual difficulties. A pre-test, post-test and control group quasi-experimental research design was used with a sample of children diagnosed with mild intellectual disability from three special schools in Ibadan, Nigeria. Fifty children were randomly selected and assigned to one of three groups: music therapy, pictorial illustration, or control $(N=50$, male $=25$, female $=25$, mean age $=11.6$ years). Twenty-four sessions of music therapy and pictorial illustration classes were held with the experimental group only. The Moss Attention Rating Scale was used before and after the intervention to collect data on participants' attention span. Analysis of Covariance indicated that there was a significant statistical difference between pre-test and post-test results of the two groups. The estimated marginal means of post-attention span by treatment indicated that pictorial illustration had the highest post-attention span score, followed by music therapy, while postattention span score for the control group was the least. Based on the findings, it is recommended that teachers, caregivers, and parents of children with mild intellectual disability adopt pictorial illustration and music therapy as teaching strategies to enhance their attention span.

Keywords: attention span, children, mild intellectual disability, music therapy, pictorial illustration

\section{INTRODUCTION}

A significant challenge faced by children with intellectual disability is the difficulty of paying attention to classroom instruction long enough to acquire the information they need to effectively participate in learning activities. Most children with intellectual disability have the ability to complete academic and non-academic tasks, but their inability to pay attention to detailed instruction frequently leads to failure. To ensure that the skills required to complete assigned responsibilities are easily developed, it is important that appropriate teaching strategies are used to enhance the attention of children with intellectual disability during teaching and learning process 
(Deutsch et al., 2008). Attention span among school-aged children is particularly crucial, as active participation (on-task and on-schedule behavior) in academic activities can contribute to improved academic performance (Carnahan et al., 2009). The term "attention" refers to the ability of an individual to concentrate their perception and thought on a specific task while deliberately ignoring extraneous stimuli (Erbay, 2013).

Attention-related issues have been, or may be, due to learning disabilities, or triggered by them. More information on attention span among children with developmental disabilities is required due to the co-morbidity of intellectual disability and attention deficit hyperactivity disorder (ADHD) (American Psychiatric Association, 2013). Various studies have shown that the child's ability to pay attention explicitly predicts academic performance. The level of children's attention functionality, according to Commodari (2012), correlates with the likelihood of developing learning disorders in a learning environment. Moreover, attention span has significant correlation with the overall achievement of a child later in life (Commodari, 2012; Gardner-Neblett et al., 2014). Attention deficit is often associated with impaired mental skills and weak impulse and behavioral control, leading the child to participate in off-task and/or destructive behavior at school (Commodari, 2012; GardnerNeblett et al., 2014).

An alerting cue can be used to establish the appropriate level of attention (Hedges et al., 2013). A child may process information efficiently using the alerting cue while their attention is focused on appropriate tasks. In essence, the relationship between attention of children with intellectual disability and the use of alerting cues should be investigated to determine their efficacy. While interventions to enhance attention span in children have been identified, most of these are ineffective for children with intellectual disability because they lack the cognitive skills to function in certain circumstances. Among the intervention strategies are visual materials, promoting predictability using routines, the use of self-discipline, music, personality-reliance instruction, applied behavior analysis, and prescription drugs (Deutsch et al., 2008; Carnahan et al., 2009; Gardner-Neblett et al., 2014). The ineffectiveness of such interventions may also be attributed to the inability of children with intellectual disability to recall information previously learnt.

For most children with intellectual disability, delays in visual processing, language processing, and comprehension of basic English are likely to lead to difficulties sustaining the required level of attention for learning. The objective of this research was to investigate the effects of music therapy and pictorial illustration on the attention span of children with mild intellectual disabilities.

\section{LITERATURE REVIEW}

\section{Benefit of Attention on Classroom Participation}

Children with intellectual disability often fail to follow instructions and seem not to be listening when directly spoken to Christiansen et al. (2015). They may demonstrate a reluctance to participate in activities that involve sustained mental energy or close attention to detail and may make careless mistakes in their work. The primary importance of attention span is to enable the child with intellectual disabilities to focus on the task for a designated amount of time (Diamond and Lee, 2011). Teachers suggest that listening to each word during the learning process makes it easier for children to develop a deeper and better understanding of classroom instruction and concepts, and reduces the time needed for revisions of what was learned afterward. Generally, teachers give their pupils this information without understanding how factual it is, or even if it is true.

Attention plays a crucial role in different cognitive activities (Gray et al., 2003), for example, spatial cognition, comprehension, long-term memory, logical thinking, and general executive functioning (Dean, 2006). Typically, a person becomes aware of the characteristics of an object when attention is paid to those objects, and the objects will fade away from consciousness as soon as attention is transferred to other objects (Laureys and Tononi, 2009). Nevertheless, Shelton et al. (2008) do not agree with the submission based on their perception that not all activities being focused on can be processed by the conscious mind, or vice versa. Schweizer (2010) argues that there are various types of attention, including: sustained attention, which involves a great deal of continuous mental effort; selective attention, also defined as intense attention; and managed attention, which refers to the controlled processing of information.

Attention is crucial part of learning. It is believed that paying attention to classroom activities can enhance the learning process, as attending lessons has a significant impact on the immediate response of pupils (Kruschke, 2005). Selective attention has been described as the most valuable aspect of learning, since it allows pupils to concentrate only on what is relevant in the learning environment (Kruschke, 2005). Children with intellectual disabilities are likely to face several additional obstacles that may distract them from learning effectively, such as the classroom arrangement, the school culture, noises from both within and outside the classroom, and the teacher's voice and teaching style. The reason why children with intellectual disability should be trained to avoid all forms of classroom distractions is that it can impede the efficient processing of information in such a learning environment.

\section{Music Therapy}

Music therapy, consisting of listening to or performing music often as a group, has been ranked among the most highly ranked forms of complementary and alternative treatments (Klein and Kemper, 2016). Therefore, music is particularly important as an avenue of social contact and non-verbal self - expression (Johnels et al., 2016). Findings have shown that the use of music as a teaching strategy is efficient in enhancing academic achievement in a variety of subject areas (Iwasaki et al., 2013). This is due to the rhythm and appealing qualities of the music, choosing songs that naturally attract the children's attention. Eren et al. (2013) and Constanti (2015), for instance, discussed the effect of music among children with special needs. Their findings inferred that music potentially reduced anxiety levels and stereotypical 
behaviors of preschoolers with special needs. Other research outcomes are convergent toward enhancing communication skills, attention span, and increasing regulation of emotions (Gooding, 2011; Nguyen, 2014).

In the submission of Kern et al. (2007), children with autism can be taught to follow classroom routine using music therapy. Sze (2006) opined that music can be incorporated into literature to assist with content engagement and to help children interact with, and participate in, specific tasks. Different researchers have focused on using music intervention to improve learning among children, irrespective of their level of ability. Songs with repetitive lyrics can be efficiently used as teaching techniques for the development of reading fluency (Iwasaki et al., 2013). Sze (2006) noted that music helped with cognitive development because of its predictable organization. In addition, according to Sze, "the integration of music provides children with tangible, hands-on interactions that are vital to the development of each child's ability to comprehend, evaluate, solve problems, assess, and promote creativity" (2006, p. 2). Psychosocial, emotional, cognitive, and communicative disorders have been successfully treated with music therapy (Baker et al., 2008). A well-known type of music therapy is Nordoff-Robbins.

In this type of music therapy, improvisation is used by therapists to make up songs that assist the client work through what they feel at a particular moment (Sorel, 2010). The use of music therapy for children with intellectual disability can help facilitate spontaneous non-verbal communication and can also teach basic skills, like reading (Register et al., 2007; Markworth, 2014). Most songs used for music therapy begin with "hello" and end with "good-bye," which establishes a routine and expresses welcome. This demonstrates that an ideal starting point to teach children with disability how to keep routines is by using music therapy (Kern et al., 2007). Carnahan et al. (2009) argued that music is efficient in enhancing participation, processing, and retention of information, and that it can also improve students learning behavior. An investigation of the impact of visual aids paired with music on the participation of students with autism during small group instruction revealed that the use of visual aids paired with music resulted in an increase of students' participation (Carnahan et al., 2009).

\section{Pictorial Illustration}

The combination of texts with images is generally perceived to have a positive effect on children's learning and attention. For example, pictorial illustrations are often used as a way of inspiring readers by making texts more appealing and interesting (Male, 2007). Not only is retention of information enhanced by pictorial illustration, but it also strengthens the ability to comprehend complex subjects that ultimately contribute to the development of appropriate problem-solving skills, provided text and images are compatible and spatially or temporally similar (Mayer, 1997, 2009; Moreno and Mayer, 1999). From a cognitive point of view, pictorial illustrations are intended to enhance ability based on the use of the multimedia effect as they present relevant information in a visual form and provide clear support for mental models of construction (Schnotz and Bannert, 2003; Schnotz, 2005; Mayer, 2009). It can be concluded that the more attention the images attract, the less distracted from learning a learner would be (Harp and Mayer, 1998; Sanchez and Wiley, 2006).

The use of pictorial illustration as a resource is common in primary school because it can help to resolve and increase understanding of concept taught and acceptance of disability among learners. Beyond learning skills through text and pictures in children's books, pictorial illustration can serve as a foundation for developing children's self-awareness and helping them to understand the culture of others around them (Cole and Valentine, 2000). The use of picture books can play a key role in the education of children to enhance learning outcomes (Golos et al., 2012). Koss (2015) also consider pictorial illustration to be one of the most important mediators for transmitting cultural awareness and social values to children, as well as an interesting tool to understand the world and solve complex problems that could define the reality in which each child lives. The characters in the illustrations can also help to enhance learning atmosphere by emphasizing diversity, social equality, tolerance, and empathy for learners with disabilities (Sigmon et al., 2016). It can, however, be a challenging process to select and use appropriate books to effectively facilitate understanding among children with special needs, particularly those with intellectual disability (Ostrosky et al., 2013).

\section{METHODOLOGY}

\section{Hypothesis}

The null hypotheses tested at 0.05 level of significance was: There is no significant main effect of treatment (music therapy and pictorial illustration) on enhancing attention span of participants.

\section{Participants}

Fifty children with mild intellectual disability were selected for the study. They were selected using a multi-stage sampling method from three special schools to reflect geographical coverage of the Ibadan metropolis, Oyo State. A purposive sampling technique was used for the selection of pupils with moderate intellectual disability based on assessment by a psychologist. Participants were assigned randomly to treatment groups tagged as $\mathrm{M}, \mathrm{P}$, and $\mathrm{C}$, representing the treatment they were exposed to. In school $\mathrm{M}$, out of a population of 32 pupils, 15 with mild intellectual disability $(N=15$, male $=8$; female $=7$; mean age $=11.8)$ were selected; in school $\mathrm{P}$, out of a population of 40 pupils, 18 with mild intellectual disability $(N=18$, male $=8$; female $=10$; mean age $=11.3$ ) were selected; and in school $\mathrm{C}$, out of 38 pupils, 17 with mild intellectual disability $(N=17$, male $=9$; female $=8$; mean age $=11.6)$ were selected. Participants in school $\mathrm{M}$ were exposed to music therapy, those in school $\mathrm{P}$ were exposed to pictorial illustration, and participants in school $\mathrm{C}$ were exposed to conventional methods of teaching, thereby serving as the control group. The reason for not exposing children from the same school to the three treatments was to avoid contamination.

\section{Materials and Methods}

The study was based on a quasi-experimental research design of the pre-test control group using a factorial matrix of 3 . Three 
levels of treatment (music therapy, pictorial illustration, and control) were considered. The design is represented thus:

Experimental Group 1: (E1) $\mathrm{O}_{1} \mathrm{X}_{1} \mathrm{O}_{4}$

Experimental Group 1: (E1) $\mathrm{O}_{2} \mathrm{X}_{1} \mathrm{O}_{5}$

Control Group 2: (E2) $\mathrm{O}_{3}$ (E2) $\mathrm{O}_{6} \mathrm{O}_{3} \mathrm{O}_{6}$

Where:

$\mathrm{O}_{1}, \mathrm{O}_{2}$, and $\mathrm{O}_{3}$ represent experimental and control group pretest scores, respectively.

$\mathrm{O}_{4}, \mathrm{O}_{5}$, and $\mathrm{O}_{6}$ represent experimental and control group post-test scores, respectively.

$\mathrm{X}_{1}$ represents the treatment for experimental group (the teaching mode of music therapy).

$\mathrm{X}_{1}$ represents the treatment for experimental group (the teaching mode of pictorial illustration).

\section{Music Therapy}

Traditional folk songs were used for the music therapy. Each session was held using drum sets, a piano and recorders. The teacher sang the song at the start of each therapy session with the support of a music therapist, and the lyrics explained to participants what attentive behaviors were expected (appropriate vocalizations, eyes on speaker/materials, appropriate hand movement, sitting upright, and still feet). The music therapy treatment consisted of twenty-four sessions of $45 \mathrm{~min}$ each for the treatment group. Participants were encouraged to sing along and dance to the music. Participant names were inserted into the songs and when necessary specific actions was taken by the participants such as dancing, stamping of the feet among others. For the control group, no intervention was used, and they were not asked to attend any music therapy sessions. Example of the sing used includes:

Bàtà mi á dún ko ko kà - My shoes will make a rich sound.

Lábẹi igi òroẹ́bó |- Under the orange tree.

\section{Pictorial Illustration}

During the pictorial illustration sessions, images and diagrams were drawn by hand. Each session was held using drawing books, pencils, and crayons. The pictorial illustration treatment consisted of twenty-four of $45 \mathrm{~min}$ each for the treatment group. Participants were encouraged to draw pictures representing their ideas and responses to questions. For the control group, no intervention was used, and they were not asked to attend any pictorial illustration sessions.

\section{Moss Attention Rating Scale}

The Moss Attention Rating Scale was designed in 2003 by John Whyte and colleagues. The scale has 22 items assessed on a five-point Likert-type scale based on how well an individual behavior is represented. The response ranged from "definitely true" to "definitely false." The phrases used for each item were such that participants were expected to perceive each behavior as an indication of ether acceptable or inappropriate attention. Most items had a relationship with the three predictor variables observed for the Moss Attention Rating Scale (MARS): restlessness, distractibility, initiation, and sustained consistent attention (Hart et al., 2006). The total raw MARS score may be converted to an interval metric from 0 to 100 . The MARS has been subjected to two large sample studies of inter-rater reliability. The first (Whyte et al., 2003) compared ratings of patients' occupational therapists (OTs) and physical therapists (PTs) done independently over the same 3-day window. The MARS was originally designed as an observational rating scale to provide a reliable $(r=0.64)$, quantitative, and ecologically valid measurement of attention-related behavior after traumatic brain injury (TBI) (Hart et al., 2009). The scale was pilot tested to determine it suitability for pupils with mid intellectual disability. It yielded a cronbach's alpha of 0.69 .

\section{Ethical Consideration}

Participant's parents were duly informed about the aim of the study by through a letter sent to them and required to be at the school on a specific day with the researcher. In line with the ethics of research, the researcher a meeting was held with participant's parents where the content of the consent form was explained to them by the a teacher who also serve as research assistant, using native language. Once adequate understanding was ensured, each parent completed and appended their signature to the consent form. Participants were assured of the confidentiality of their profiles and responses. One major restriction in the study was that the sessions was not recorded.

\section{Procedure}

The local education authority granted approval to conduct the study and were informed of its purpose. An introduction was presented to the head of the selected school. Three research assistants served as resource teachers for the three groups. Teacher of children with special needs implemented the music therapy while trained therapist assisted so that it can be appropriately carried out. They were trained during sessions of $5 \mathrm{~h}$ each for 3 days on how to provide the intervention to participants. After that, the attention span scale was administered to selected children with intellectual disability. The data collected was the pretest score. The intervention lasted for 8 weeks, with 45 min sessions. Placebo treatment was given to the control group (conventional method). The instrument used during the pretest was also used to evaluate the treatment and control group as the post-test after the 8 weeks of intervention.

\section{Data Analysis}

The data generated were analyzed using Analysis of Covariance (ANCOVA) to test the null hypotheses at 0.05 level of significance difference. Moreover, the estimated marginal means and Bonferroni post hoc results were determined.

\section{RESULTS}

$\mathrm{H}_{o 1}$ : There is no significant main effect of treatment on attention span of children with intellectual disability.

Table 1 shows that there was significant main effect of treatment in enhancing attention span of children with intellectual disability $\left[F_{(2,35)}=443.582 ; p<0.05\right.$; partial $\left.\eta^{2}=0.962\right]$. The effect size is $96.2 \%$. This implies that $96.2 \%$ variance in the post-reading performance of learners with intellectual disability was accounted for by treatment, hence, there was a significant difference in the attention span of children 
with intellectual disability Therefore, the null hypothesis was not accepted. The level of significant main effect was determined groups using estimated marginal means of the treatment groups and the result is presented in Table 2.

Table 2 shows that the learners with intellectual disability in the pictorial illustration group had the highest post-attention span score (34.076), followed by music therapy (24.160), while the students in the conventional group had the lowest mean score (14.373). This order could be represented as PI $>$ MT $>$ CS.

Table 3 shows that there was a significant difference in the post-reading performance of students in the music therapy and pictorial illustration groups (Mean difference $=-9.916$; $p<0.05$ ); music therapy and conventional (Mean difference $=9.787 ; p<0.05)$; and pictorial illustration and conventional (Mean difference $=19.704 ; p<0.05$ ).

\section{Discussion of Findings}

Based on the hypothesis, the results show that treatment (music therapy and pictorial illustration) had a significant effect on the attention span of children with intellectual disabilities. This is consistent with the suggestion of Sze and Yu (2004) that integrating music and learning for students could provide opportunities for realistic, hands-on interactions that are important for the development of each student's ability to reason, reflect and resolve conflicts. This shows that that music can be used effectively for the management of medical and psychological challenges. Furthermore, music therapy as an intervention, it has improved motor performance in children and coordination and strength in children with ID (Ekins et al., 2019). The intervention group of the present study participated in a multidimensional movement of activity during the intervention that stimulated all sensory systems.

These findings are consistent with recent studies suggested that regular physical activity programs such as music that will allow participants to move their body had positive effects on the social and school behavior characteristics of individuals with Intellectual Disabilities (Best, 2010; Brooks et al., 2015; Güvendi and İlhan, 2017; Yílmaz and Soyer, 2018). Moreover, present finding on the effect of pictorial illustration on attention span aligns with previous research submission that a temporal relationship exist between information processed visually and verbally (Hill, 2003; Butcher and Vincent, 2007; Özdemir, 2007). In the opinion of Bruscia (2014) music centered interactions are an undeniable aspect of music therapy, where music is the acting motivator because music contributes to therapy as a tool, a process and an outcome.

TABLE 1 | Analysis of covariance of post-attention span of children with intellectual disability by treatment.

\begin{tabular}{|c|c|c|c|c|c|c|}
\hline Source & Type III sum of squares & Df & Mean square & $\boldsymbol{F}$ & Sig. & Partial eta squared \\
\hline Corrected model & 1979.691 & 8 & 247.461 & 139.207 & 0.000 & 0.970 \\
\hline Intercept & 143.576 & 1 & 143.576 & 80.767 & 0.000 & 0.698 \\
\hline Pre-test & 68.723 & 1 & 68.723 & 38.659 & $0.000^{\star}$ & 0.525 \\
\hline Treatment & 1577.064 & 2 & 788.532 & 443.582 & $0.000^{*}$ & 0.962 \\
\hline Error & 62.218 & 35 & 1.778 & & & \\
\hline Total & 31890.000 & 44 & & & & \\
\hline Corrected total & 2041.909 & 43 & & & & \\
\hline
\end{tabular}

*Significant.

TABLE 2 | Estimated marginal means of post-attention span by treatment.

\begin{tabular}{|c|c|c|c|c|}
\hline \multirow[t]{2}{*}{ Treatment } & \multirow[t]{2}{*}{ Mean } & \multirow[t]{2}{*}{ Std. error } & \multicolumn{2}{|c|}{$95 \%$ confidence interval } \\
\hline & & & Lower bound & Upper bound \\
\hline Music therapy & 24.160 & 0.310 & 23.530 & 24.789 \\
\hline Pictorial illustration & 34.076 & 0.406 & 33.253 & 34.900 \\
\hline Conventional & 14.373 & 0.478 & 13.402 & 15.343 \\
\hline
\end{tabular}

TABLE 3 | Bonferroni post hoc analysis of the reading performance by treatment.

\begin{tabular}{|c|c|c|c|c|c|c|}
\hline \multirow[t]{2}{*}{ (I) Treatment } & \multirow[t]{2}{*}{ (J) Treatment } & \multirow[t]{2}{*}{ Mean difference (I-J) } & \multicolumn{2}{|c|}{ Std. error } & \multirow{2}{*}{$\frac{\text { Sig. }^{d}}{\text { Lower bound }}$} & \multirow{2}{*}{$\frac{95 \% \text { confidence interval for difference }}{d}$} \\
\hline & & & & & & \\
\hline \multirow[t]{2}{*}{ Music therapy } & Pictorial illustration & $-9.916^{\star}$ & 0.521 & 0.000 & -11.226 & -8.607 \\
\hline & Conventional & $9.787^{*}$ & 0.563 & 0.000 & 8.370 & 11.204 \\
\hline \multirow[t]{2}{*}{ Pictorial illustration } & Music therapy & $9.916^{\star}$ & 0.521 & 0.000 & 8.607 & 11.226 \\
\hline & Conventional & $19.704^{*}$ & 0.642 & 0.000 & 18.090 & 21.317 \\
\hline \multirow[t]{2}{*}{ Conventional } & Music therapy & $-9.787^{*}$ & 0.563 & 0.000 & -11.204 & -8.370 \\
\hline & Pictorial illustration & $-19.704^{*}$ & 0.642 & 0.000 & -21.317 & -18.090 \\
\hline
\end{tabular}

* indicate result is significant. 
Furthermore, the estimated marginal means of post-attention span by treatment revealed that pictorial illustration had the highest post-attention span score, followed by music therapy, while the control group had the lowest post-attention span score. The present findings are consistent with the report of Ryu, cited in Roslina (2017), that using dual coding theory (visual and verbal mode) for processing information constitute a challenge, when the system to process the information is more than one. This shows that it is more efficient using two sources of information during classroom activities because it will enhance attention span required for improving comprehension. Moreover, pictorial illustration was used as a means of motivating and engaging pupils, thereby increasing student achievement. The estimated marginal means for music therapy is not consistent with the submission of Anderson and Fuller (2010), who reported a significant decline in reading comprehension after pupils listened to lyrical music, compared to the control group that read in a quiet environment. The result is, however, consistent with the previous report that music has a positive effect on increasing on-task behavior (Dieringer et al., 2017) and decreasing off-task behavior (Titus and Porretta, 2012) for children with ASD.

\section{CONCLUSION AND RECOMMENDATIONS}

Based on the findings of the study, it can be concluded that treatment (music therapy and pictorial illustration) had a significant effect on the attention span of children with intellectual disability when compared to participants in the control group. The reason for the effectiveness of music therapy could be due to the active participation of learners in singing the songs (traditional folk songs were used) and in that way the interest of the learners was better sustained in comparison to participants in the control group. Pictorial illustration was the more efficient of the two treatments in sustaining the attention of children with intellectual disability. This was probably due to the opportunity created for the learners to interact with one another while learning through pictures. Music therapy and pictorial illustration are learner-centered instructional strategies which will increase the active participation of learners in any learning environment.

The implication of these findings is that the use of the two strategies (music therapy and pictorial illustration) to enhance the attention of children with intellectual disability should be encouraged among their teachers. This is because both strategies enhance the attention of children with intellectual disability required for active classroom participation. In that way, learning is made concrete, auditory, and visual. Since pictorial illustration had a more significant effect in enhancing the attention span of children with intellectual disability, teachers should consider their use to encourage learners' active participation in learning tasks. It is, therefore, recommended that stakeholders such as teachers, caregivers, and parents of children with intellectual disability, should be trained on how pictorial illustration and music therapy can be applied to attract the attention of children with intellectual disability.

\section{LIMITATIONS}

The small sample size was one of the study's limitation. Future research should include a larger number of participants. Due to the unpredictability of a variety of factors, conducting the study in a school setting was also a limitation. These factors include participant absences, pupil behavior (which can sometimes be distracting to other pupils and necessitate the removal of staff from the academic setting to deal with behaviors), and scheduled days off from school. Another limitation to the study is one person serving as assessor of the participants' attention-related behavior in each treatment group. This did not allow for opportunity to compare the degree of agreement or disagreement of observed behavior.

\section{DATA AVAILABILITY STATEMENT}

The original contributions presented in the study are included in the article/supplementary material, further inquiries can be directed to the corresponding author/s.

\section{ETHICS STATEMENT}

The studies involving human participants were reviewed and approved by the University of Ibadan. Written informed consent to participate in this study was provided by the participants' legal guardian/next of kin.

\section{AUTHOR CONTRIBUTIONS}

$\mathrm{UJ}$ conceived the research and did the data collection. JP and EO worked and edited the manuscript. All authors contributed to the article and approved the submitted version.

\section{FUNDING}

This work was supported by the South African Research Chairs Initiative of the Department of Science and Innovation and National Research Foundation of South Africa, South African Research Chair in Education and Care in Childhood, Faculty of Education, University of Johannesburg, South Africa (grant number: 87300, 2017). 


\section{REFERENCES}

American Psychiatric Association (2013). Diagnostic and Statistical Manual of Mental Disorders, 5th Edn. Washington, D.C.: American Psychiatric Association.

Anderson, S. A., and Fuller, G. B. (2010). Effect of music on reading comprehension of junior high school students. School Psychol. Quar. 25, 178-187. doi: 10.1037/ a0021213

Baker, F., Wigram, T., Stott, D., and McFerran, K. (2008). Therapeutic songwriting in music therapy. Part $\mathrm{I}$ : who are the therapists, who are the clients, and why is songwriting used? Nordic J. Music Therapy 17, 105-123. doi: 10.1080/0809813080947 8203

Best, J. R. (2010) Effects of physical activity on children's executive function: contributions of experimental research on aerobic exercise. Dev Rev 30, 331351. doi: 10.1016/j.dr.2010.08.001

Brooks, B. A., Floyd, F., Robins, D. L., and Chan, W. Y. (2015). Extracurricular activities and the development of social skills in children with intellectual and specific learning disabilities. J. Intellect. Disabil. Res. 59, 678-687. doi: 10.1111/ jir.12171

Bruscia, K. E. (2014). Defining Music Therapy, 3rd Edn. Barcelona Publishers.

Butcher, K., and Vincent, A. (2007). "Integrating visual and verbal knowledge during classroom learning with computer tutors," in Proceedings of the Annual Meeting of the Cognitive Science Society. Austin: Cognitive Science Society.

Carnahan, C., Musti-Rao, S., and Bailey, J. (2009). Promoting active engagement in small group learning experiences for students with autism and significant learning needs. Educ. Treatment Children 32, 37-61. doi: 10.1353/etc.0. 0047

Christiansen, H., Hirsch, O., König, A., Steinmayr, R., and Roehrle, B. (2015). Prevention of ADHD related problems: a universal preschool program. Health Educ. 115, 285-300. doi: 10.1108/HE-03-2014-0040

Cole, E. M., and Valentine, D. P. (2000). Multiethnic children portrayed in children's picture books. Child Adolescent Soc. Work J. 17, 305-317. doi: 10 1023/A:1007550124043

Commodari, E. (2012). Attention skills and risk of developing learning difficulties. Curr. Psychol. 31, 17-34. doi: 10.1007/s12144-012-9128-3

Constanti, F. A. (2015). Emotional effects of music therapy on children with special needs. J. Plus Educ. 12A, 178-183.

Dean, S. (2006). Understanding an Achievement Gap: Exploring the Relationship Between Attention, Working Memory and Academic Achievement (UMI No. 3209993). thesis, Philadelphia, PA: University of Pennsylvania.

Deutsch, C. K., Dube, W. V., and McIlvane, W. J. (2008). Attention deficits, attention-deficit hyperactivity disorder, and intellectual disabilities. Dev. Disabil. Res. Rev. 14, 285-292. doi: 10.1002/ddrr.42

Diamond, A., and Lee, K. (2011). Interventions shown to aid executive function development in children 4 to 12 years old. Science 333, 959-964. doi: 10.1126/ science.1204529

Dieringer, S. T., Porretta, D. L., and Sainato, D. (2017). Music and On-Task behaviors in preschool children with autism spectrum disorder. Adapted Phys. Act. Quar. 34, 217-234. doi: 10.1123/apaq.2015-0033

Ekins, C., Boehr, J., Schulz, H., Wright, P. R., Owens, D., and Miller, W. (2019). Effects of a drums alive kids beats intervention on motor skills and behavior in children with intellectual disabilities. Palaestra 33, 16-25.

Erbay, F. (2013). Predictive power of attention and reading readiness variables on auditory reasoning and processing skills of six-year-old children. Educ. Sci. Theory Practice 13, 422-429.

Eren, B., Deniz, J., and Düzkantar, A. (2013). The effectiveness of embedded teaching through the most-to-least prompting procedure in concept teaching to children with autism within Orff-based music activities. Educ. Sci. Theory Practice 13, 1877-1885. doi: 10.12738/estp.2013.3.1499

Gardner-Neblett, N., DeCoster, J., and Hamre, B. K. (2014). Linking preschool language and sustained attention with adolescent achievement through classroom self-reliance. J. Appl. Dev. Psychol. 35, 457-467. doi: 10.1016/j. appdev.2014.09.003

Golos, D. B., Moses, A. M., and Wolbers, K. A. (2012). Culture or disability? examining deaf characters in children's book illustrations. Early Childhood Educ. J. 40, 239-249. doi: 10.1007/s10643-012-0506-0
Gooding, L. F. (2011). The effect of a music therapy social skills training program on improving social competence in children and adolescents with social skills deficits. J. Music Ther. 48, 440-462. doi: 10.1093/jmt/48.4.440

Gray, J. R., Chabris, C. F., and Braver, T. S. (2003). Neural mechanisms of general fluid intelligence. Nat. Neurosci. 6, 314-322. doi: 10.1038/nn1 014

Güvendi, B., and İlhan, E. L. (2017). Effects of adapted physical activity applied on intellectual disability students toward level of emotional adjustment, selfmanaging and the socialization: parent and teacher interactive research. J. Hum. Sci. 14, 3879-3894. doi: 10.14687/jhs.v14i4.4812

Harp, S. F., and Mayer, R. E. (1998). How seductive details do their damage: a theory of cognitive interest in science learning. J. Educ. Psychol. 90, 414-434. doi: $10.1037 / 0022-0663.903 .414$

Hart, T., Whyte, J., Ellis, C., and Chervoneva, I. (2009). Construct validity of an attention rating scale for traumatic brain injury. Neuropsychology 23, 729-735. doi: $10.1037 / \mathrm{a} 0016153$

Hart, T., Whyte, J., Millis, S., Bode, R., Malec, J., Richardson, R. N., et al. (2006). Dimensions of disordered attention in traumatic brain injury: further validations of the moss attention rating scale. Arch. Phys. Med. Rehabil. 87, 647-655. doi: 10.1016/j.apmr.2006.01.016

Hedges, J. H., Adolph, K. E., Amso, D., Bavelier, D., Fiez, J. A., Krubitzer, L., et al. (2013). Play, attention, and learning: how do play and timing shape the development of attention and influence classroom learning? Ann. N. Y. Acad. Sci. 1292, 1-20. doi: 10.1111/nyas.12154

Hill, D. A. (2003). "The visual elements in EFL coursebooks," in Developing Materials for Language Teaching, ed. B. Tomlinson (London: Continuum), $174-182$.

Iwasaki, B., Rasinski, T., Yildirim, K., and Zimmerman, B. S. (2013). Let's bring back the magic of song for teaching reading. Read. Teacher 67, 137-141. doi: 10.1002/TRTR.1203

Johnels, J. Å, Johnels, L., and Rådemark, C. (2016). Fostering high-quality social interaction together with individuals with profound intellectual disability. Nordic J. Music Therapy 25, 118-119. doi: 10.1080/08098131.2016.1180210

Kern, P., Wolery, M., and Aldridge, D. (2007). Use of songs to promote independence in morning greeting routines for young children with autism. J. Autism Dev. Disord. 37, 1264-1271. doi: 10.1007/s10803-006-0272-1

Klein, N., and Kemper, K. J. (2016). Integrative approaches to caring for children with autism. Curr. Probl. Pediatr. Adolesc. Health Care 46, 195-201. doi: 10. 1016/j.cppeds.2015.12.004

Koss, M. D. (2015). Diversity in contemporary picturebooks: a content analysis. J. Children's Literature 41, 32-42.

Kruschke, J. (2005). "Learning involves attention," in Connectionist Models in Cognitive Psychology, ed. G. Houghton (Milton Park: Psychology Press).

Laureys, S., and Tononi, G. (2009). The Neurology of Consciousness: Cognitive Neuroscience and Neuropathology, 1st Edn. Amsterdam: Elsevier.

Male, A. (2007). Illustration: A Theoretical and Contextual Perspective. Worthing: Ava Book.

Markworth, L. (2014). "Without words: music as communication for children with autism," in Qualitative Inquiries in Music Therapy, ed. D. Keith (Barcelona: Barcelona Publishers).

Mayer, R. E. (1997). Multimedia learning: are we asking the right questions? Educ. Psychol. 32, 1-19. doi: 10.1207/s15326985ep3201_1

Mayer, R. E. (2009). Multimedia Learning, 2nd Edn. Cambridge: Cambridge University Press.

Moreno, R., and Mayer, R. E. (1999). Cognitive principles of multimedia learning: the role of modality and contiguity. J. Educ. Psychol. 91, 358-368. doi: 10.1037/ 0022-0663.91.2.358

Nguyen, A. (2014). Using classical music to increase productivity in elementary school students with attention deficit hyperactivity disorder. Undergraduate Res. Posters Poster 57, 15-17.

Ostrosky, M. M., Mouzourou, C., Dorsey, E. A., Favazza, P. C., and Leboeuf, L. M. (2013). Pick a book, any book: using children's books to support positive attitudes toward peers with disabilities. Young Except. Children 18, 30-43. doi: $10.1177 / 1096250613512666$

Özdemir, F. E. (2007). An Evaluation of Time for English 4, the 4th Grade English course book for public schools. Master's thesis, Ankara: Middle East Technical University. 
Register, D., Darrow, A.-A., Standley, J., and Swedbert, O. (2007). The use of music to enhance reading skills of second grade students and students with reading disabilities. J. Music Ther. 44, 23-37. doi: 10.1093/jmt/44. 1.23

Roslina. (2017). The effect of picture story books on students' reading comprehension. Adv. Lang. Literary Stud. 8, 213-221. doi: 10.7575/aiac.alls.v. 8n.2p.213

Sanchez, C. A., and Wiley, J. (2006). An examination of the seductive details effect in terms of working memory capacity. Memory Cogn. 34, 344-355. doi: 10.3758/BF03193412

Schnotz, W. (2005). "An integrated model of text and picture comprehension," in Cambridge Handbook of Multimedia Learning, ed. R. E. Mayer (Cambridge: Cambridge University Press), 49-69. doi: 10.1017/cbo978051181681 9.005

Schnotz, W., and Bannert, M. (2003). Construction and interference in learning from multiple representations. Learn. Instruct. 13, 141-156. doi: 10.1016/ S0959-4752(02)00017-8

Schweizer, K. (2010). "The relationship of attention and intelligence," in Handbook of Individual Differences in Cognition, eds A. Gruszka, G. Matthews, and B. Szymura (Berlin: Springer), 247-259. doi: 10.1007/978-1-4419-12 10-7_15

Shelton, J., Elliott, E., and Cowan, N. (2008). Attention and working memory: tools for understanding consciousness. Psyche 14, 1-6.

Sigmon, M. L., Tackett, M. E., and Azano, A. P. (2016). Using children's picture books about autism as resources in inclusive classrooms. Read. Teacher 70, 111-117. doi: $10.1002 /$ trtr.1473
Sorel, S. (2010). Presenting carly and elliott: exploring roles and relationships in a mother-son dyad in nordoff-robbins music therapy. Qual. Inquiries Music Therapy 5, 173-238.

Sze, S. (2006). Empowering students with disabilities through music integration in the classroom: music therapy on student. Acad. Educ. Leadership J. 10, 113-118.

Sze, S., and Yu, S. (2004). Educational Benefits of Music in an Inclusive Classroom. Available online at: http://files.eric.ed.gov/fulltext/ED490348.pdf

Titus, S., and Porretta, D. L. (2012). Using Music to Decrease Off-task Behavior for Children with Autism. Reston, VA: Research Quarterly for Exercise and Sport.

Whyte, J., Hart, T., Bode, R. K., and Malec, J. F. (2003). The moss attention rating scale for traumatic brain injury: initial psychometric assessment. Arch. Phys. Med. Rehabil. 84, 268-276. doi: 10.1053/apmr.2003.50108

Yílmaz, A., and Soyer, F. (2018). Effect of physical education and play applications on school social behaviors of mild-level intellectually disabled children. Educ. Sci. 8:89. doi: 10.3390/educsci 8020089

Conflict of Interest: The authors declare that the research was conducted in the absence of any commercial or financial relationships that could be construed as a potential conflict of interest.

Copyright (C) 2021 Jacob, Pillay and Oyefeso. This is an open-access article distributed under the terms of the Creative Commons Attribution License (CC BY). The use, distribution or reproduction in other forums is permitted, provided the original author(s) and the copyright owner(s) are credited and that the original publication in this journal is cited, in accordance with accepted academic practice. No use, distribution or reproduction is permitted which does not comply with these terms. 